\title{
Fully Automated Hydroponics System for Smart Farming
}

\author{
Hariram M Shetty \\ Information Science and Engineering, Canara Engineering College, Mangalore \\ Email: hariram.hmshetty@gmail.com
}

\section{Kshama Pai K}

Information Science and Engineering, Canara Engineering College,Mangalore

Email: kshamapaik@gmail.com

\author{
Navaneeth Mallya \\ Information Science and Engineering, Canara Engineering College, Mangalore, \\ Email: navaneethmallya1999@gmail.com

\section{Pratheeksha} \\ Information Science and Engineering, Canara Engineering College,Mangalore \\ Email: anchanpk@gmail.com
}

Received: 10 June 2021; Accepted: 11 July 2021; Published: 08 August 2021

\begin{abstract}
This project is focused on developing a Fully Automatic Hydroponics system which helps in monitoring and controlling temperature, Humidity, $\mathrm{pH}$ and EC in Hydroponics. Hydroponics is a method of growing crops without soil. Plants are grown in rows or on trellises, just like in a traditional garden, but they have their roots in water rather than in dirt. Although, there are different ways in which hydroponics can be implemented, there is no individual system which can measure and control $\mathrm{pH}$ and EC level of nutrient solution along with its surrounding temperature and humidity automatically. We use PIC16F877A microcontroller and four pumps, three of which are used to pump water, nutrient solution, $\mathrm{pH}$ solution and the fourth pump is used to control the humidity. A fan is used to control the temperature which increases its speed as the temperature increases. The pumps are turned on depending on the EC and $\mathrm{pH}$ values obtained from the electrodes. A passive LCD display is used to display variations in the values. Different Analysis like water usage, plant growth in comparison with regular farming method and hydroponics is successfully completed which results in hydroponics system is significant method in comparison with soiled cultivation method in terms of yield and water usage. This project is expected to produce high yield crops by taking minimal space, makes work easier for farmers in growing of plants, and also consumes less amount of water when compared to traditional method resulting in conservation of water.
\end{abstract}

Index Terms: PIC16F877A micro controller, EC and pH electrode, Soil-less farming, Deep Water Culture.

\section{Introduction}

The aim of this project is to develop a fully automated hydroponics system which can monitor and control temperature, Humidity, $\mathrm{pH}$ and EC without any manual support. Although there are individual digital $\mathrm{pH}$ meters and TDS meters to measure $\mathrm{pH}$ and $\mathrm{EC}$ value of the nutrient solutions are available and other sensors to measure parameters like temperature and Humidity. But no individual system is available to measure all these parameters and control its parameters automatically. Since every plant has different ranges of $\mathrm{pH}$ and EC for different growth stages and seasons, specific nutrients are required as per plant. It is difficult for farmers keep track of them and manually control its $\mathrm{pH}$ and EC range.

Hydroponics is a type of cultivation method which uses only water mixed with nutrient solution to grow plants without using soil. This method helps farmers to grow crops efficiently and more productive way using less water, labour and time. Soil is not required for the plant to grow but it acts as a base to provide all the nutrients for the growth of the plant. By providing these nutrients through water externally with external support to hold the plant, water can take over soil. In hydroponics we externally provide nutrients that plant required to grow and develop. Nutrients 
required by the plant are mixed within water and thus directly providing the nutrients to plant roots. All plants will get an equal share of nutrients which leads all plants to grow equally of all the time. It has a better nutrient value compare to the soil because of no waste of nutrients and water in soil-less cultivation methods. Hydroponics can be used to cultivate various type of plants like leafy crops, lettuce and fruit bearing plants like tomatoes, cucumbers, herbs and peppers etc. The hydroponic cultivation method required to have controlled temperature and humidity surroundings, $\mathrm{pH}$ and EC values of the nutrient solution are to be well maintained in the required range. Many commercial hydroponic farmers use the controlled greenhouse environment to get the highest quality product on a year round basis.

There are several applications that are used in the field of hydroponics, out of which "Deep-Water Culture" method is most significantly used. The major limitation of this system is that it requires user interventions. Our system fully automates working of the system which will reduce user work.

\section{Literature Survey}

"Automated pH Controller System for Hydroponic Cultivation" [1] have developed an automated pH controller system. Hydroponics is the procedure of growing plants in nutrient solutions instead of using soil. There are different types of hydroponics technique. The Deep Water Culture (DWC) is a technique where the plants are submerged in the nutrient solution and nutrients are directly passed to its roots. However, this technique requires manual control of $\mathrm{pH}$ in the solution which can affect the growth of the plant.

"Design of Efficient Hydroponic Nutrient Solution Control System using Soft Computing based Solution Grading" [2] introduces genetic algorithm based nutrient control system. The novel mamdani fuzzy inference system (FIS) is used as fitness function as it grades the quality of solution present. Using Lab view a virtual hydroponic control system is designed to check to performance of the algorithm The designed algorithm showed better convergence efficiency and resource utilization.

"Design of Fully Automated Low Cost Hydroponic System using Lab view and AVR Microcontroller" [3] proposes a method to effectively use the data in real time to influence the counteractive steps. This aims at building an self controlled system which is smart and intelligent by using present technologies. The real time data will be sent from AVR micro controller to monitor using NI Lab View and send the data to the IOT applications over the network .

"Ontology-Based Nutrient Solution Control System for Hydroponics" [4] paper proposes the Ontology-based Nutrient Solution Control System for Hydroponics using Protégé. Electrical conductivity (EC), pH, intensity of solution, species of plants and the relation of the device in the system help to find the suitable decisions to control system of hydroponics nutrient solution.

"Electrical Conductivity Measurement Method in Seawater Desalination Based on Variable Frequency Excitation" [5] proposes a method of variable frequency excitation by analysing the shortcomings of traditional measurement methods. It analyzes Temperature, electrode polarization and capacitance effect which can cause measurement errors. It was found that variable frequency method was effective in preventing the errors caused by these factors.

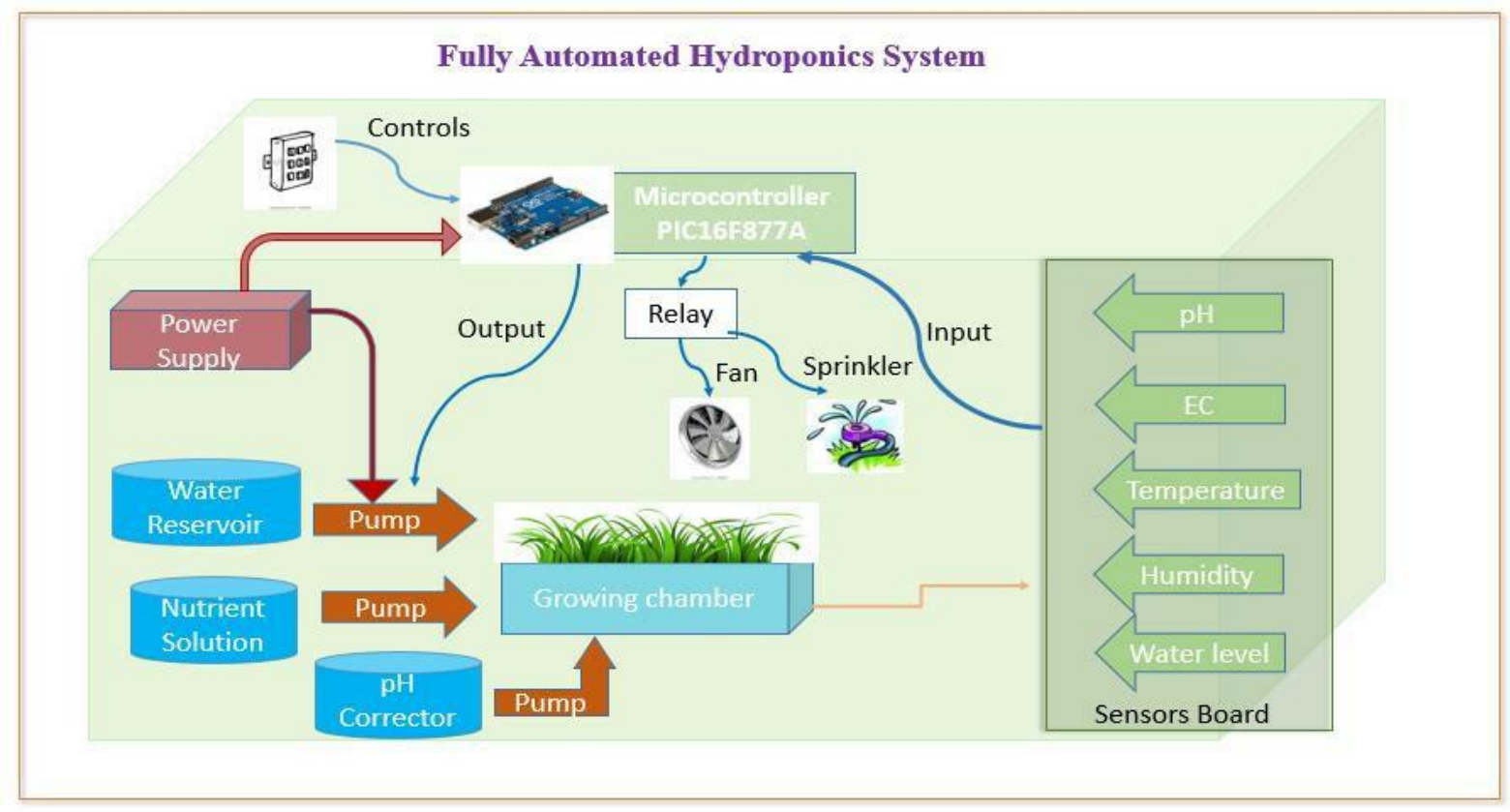

Fig. 1 Architecture Diagram 
"An Overview on pH Measurement Technique and Application in Biomedical and Industrial Process" [6] proposes a theory how $\mathrm{pH}$ value is used to determine acidity of water solution and its importance in biomedical and industry. The invasively $\mathrm{pH}$ measurement technique has to be upgraded to non-invasively technique to fulfil requirements.

"A Development of an Automatic Microcontroller System for Deep Water Culture (DWC)" [7] proposes that terrestrial plants may be grown with their roots in the mineral nutrient solutions only or in an inert medium. One of the hydroponic types was Deep Water Culture (DWC). The advantage of DWC system is highly oxygenated uses less fertilizer and low maintenance cost and monitoring time.

\section{Design}

\subsection{Architecture Diagram}

1. Hydroponic system has a growing chamber and a tray, water reservoir, Nutrient solution, delivery system or submersible pump, growing medium.

2. A sensor is used to sense the Temperature and Humidity of the surroundings and that is fed to a Microcontroller which turns on the sprinkler and fan if the temperature and humidity is out of the specified value.

3. Growing chamber contains a mixture of water and Nutrient solution whose $\mathrm{pH}$ and EC value is sensed regularly using $\mathrm{pH}$ and EC electrodes and fed to the Microcontroller depending on its $\mathrm{pH}$ and $\mathrm{EC}$ range and mode of operation selected from the Keypad. To adjust EC, water is added if the measured value is higher than the range specified and nutrient solution is added if the measured value is lower than the range specified. To adjust $\mathrm{pH}$, Sodium bicarbonate is added to increase the $\mathrm{pH}$ and Citric acid is added to decrease $\mathrm{pH}$ value.

4. $\mathrm{C}$ and $\mathrm{pH}$ ranges vary from plant to plant, Nutrient solution requirement of the plant is directly dependent on the growth stage of the plant, which causes EC ranges to vary for different growth stage (mode), by using keypad control proposed project provide full control on system to farmer giving option to change the mode and its ranges whenever required.

5. Water level sensor is used to control the water level of the growing chamber to avoid overflowing of nutrient solutions during automatic adjustment.

6. For on-site control of parameters and control of mode of operation and to add and save the range of values to system, depending on crop they are planting, key pad control is provided to the system with memory attached to the controller to store new values along with default values, giving the option to switch back to default values in emergency conditions.

\subsection{Block Diagram}

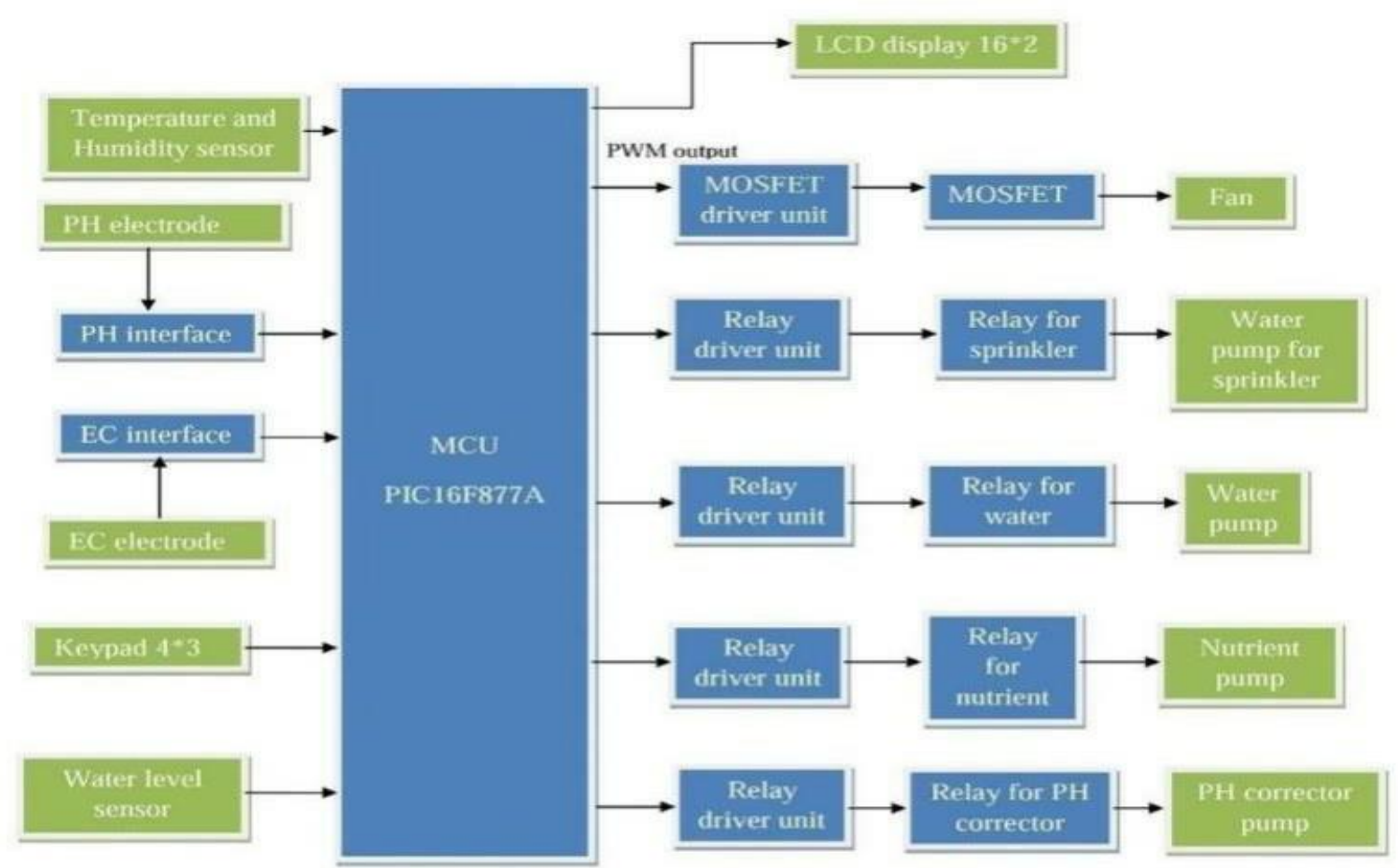

Fig. 2 Represents the Architectural Design 
The fig 2 indicates the block diagram of the fully automated hydroponics system. It measures three parameters i.e. temperature and Humidity of surroundings, water level, $\mathrm{pH}$ and EC of Nutrient Solution. It will control temperature and humidity to keep it in it specified range. Automatically Control the $\mathrm{pH}$ and EC of the Nutrient Solution by pumping Nutrient Solution, water and $\mathrm{pH}$ correctors as per required.

\section{Implementation}

Below Flowcharts represents complete automated hydroponic system. Figure 3 represents the complete flow of work in the system. The micro controller will check for EC and $\mathrm{pH}$ in real time and based on the given conditions will channel the flow of nutrient solution or water into the containment chamber. Based on the modes that are selected, user can either change modes or check the the settings using the keypad provided. All the corresponding values will be displayed on the LCD screen.
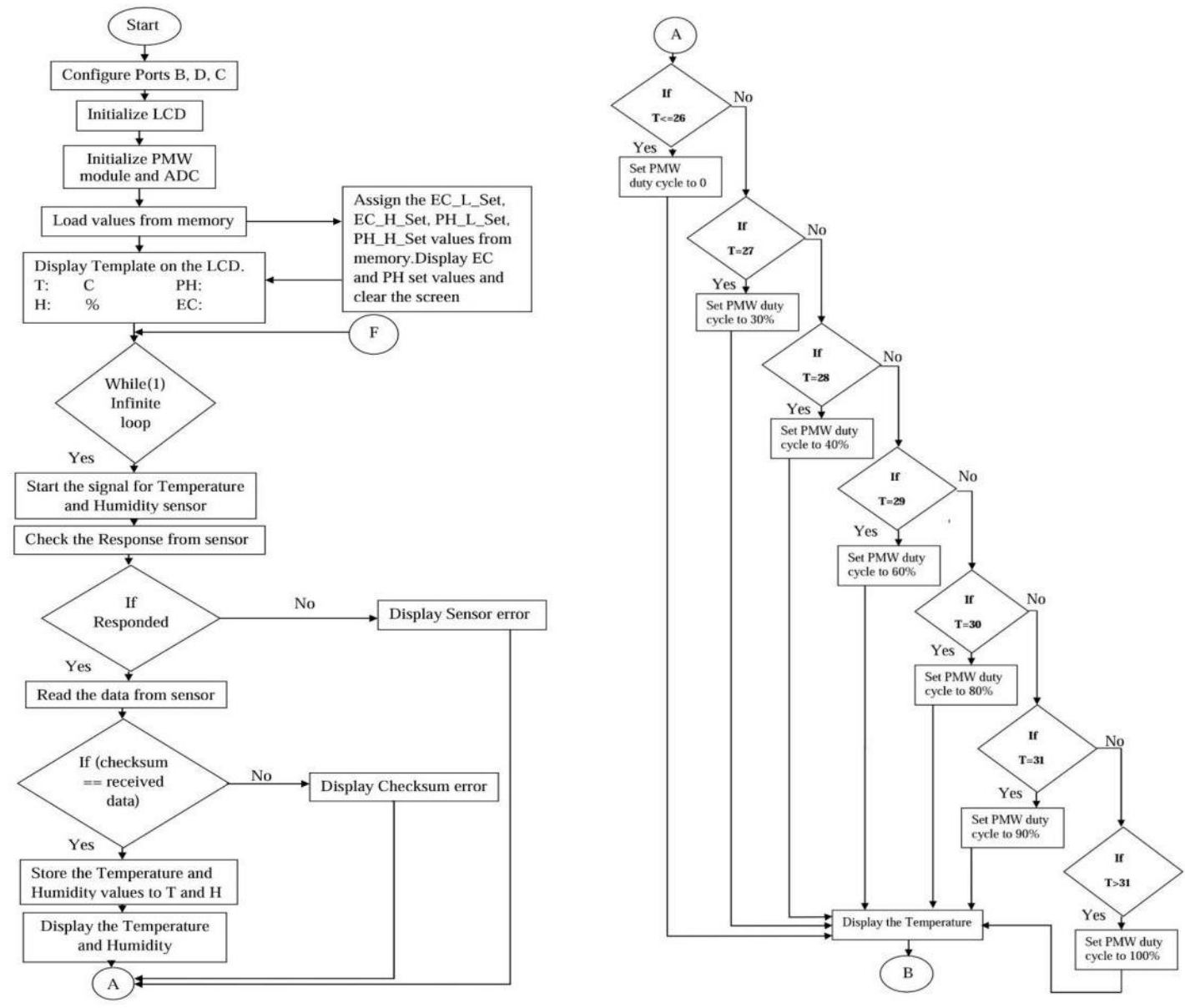

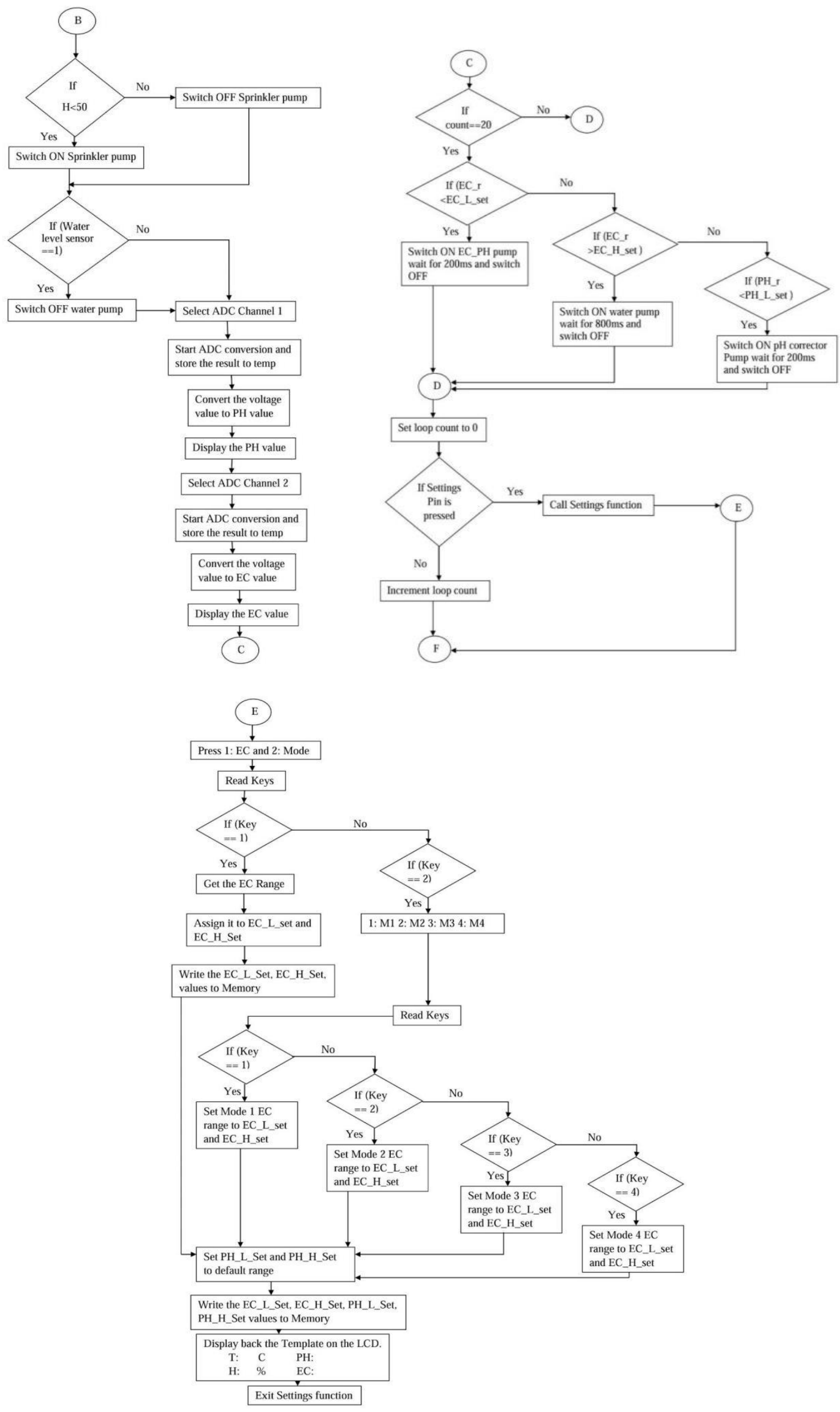

Fig. 3. Flow of Control of entire system 
The micro controller chosen for the project is PIC 16F877A. This micro controller's block diagram is shown in the fig 4 , and its pin description is shown in the fig 5 .

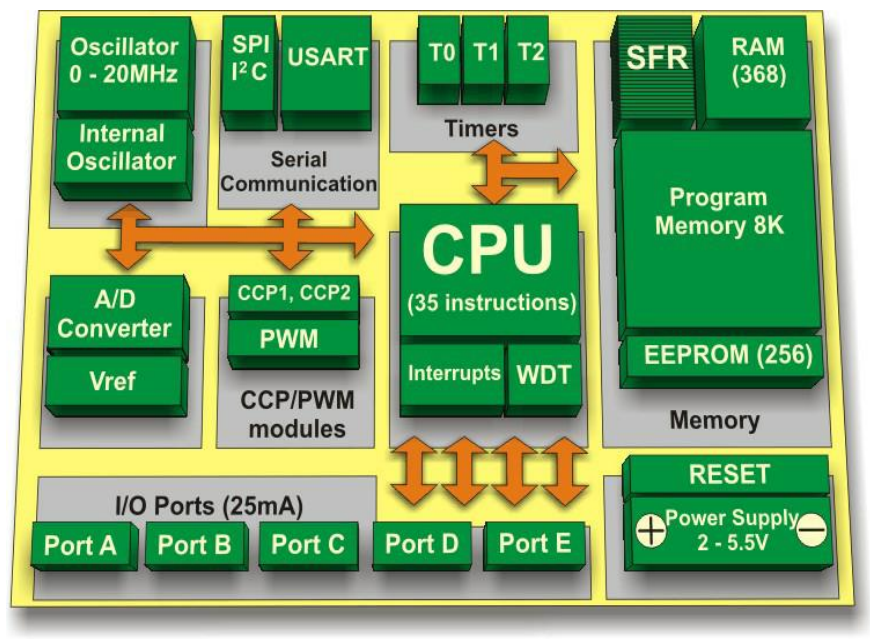

Fig. 4 Block Diagram of PIC Micro controller 16F877A.

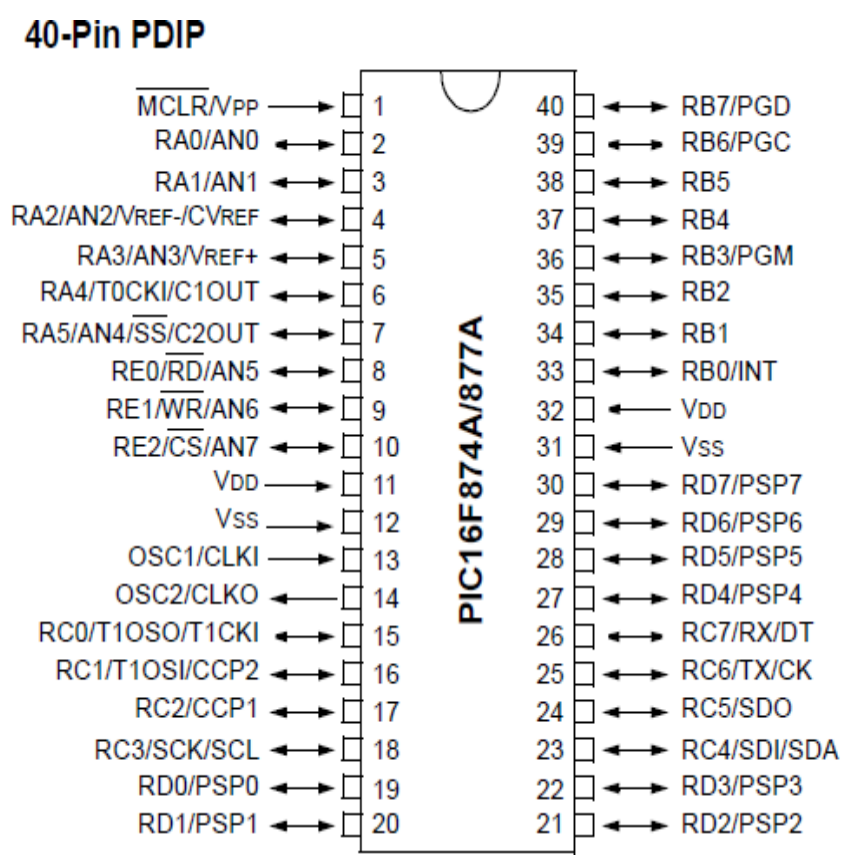

Fig. 5 Pin Diagram of PIC16F887/877A.

Mp LAB is used as and IDE to develop software part of the proposed project and Embedded $\mathrm{C}$ is used as the programming language to program code for the PIC micro controller.

\section{Result}

Figure 6 shows entire hydroponic system. The plant growing in the solution chamber. Nutrient solution is passed into this chamber using pumps and pipes.To balance the $\mathrm{pH}$ value in the chamber $\mathrm{pH}$ corrector solution is used. Temperature and Humidity sensor is also present to check the corresponding value inside the chamber. $\mathrm{pH}$ value of the solution is constantly sensed by the $\mathrm{pH}$ electrode which is connected to $\mathrm{pH}$ interface using BNC connector. " Analog-toDigital " converter will convert analog $\mathrm{pH}$ value signals into digital signals. LCD screen will display all the required values to the user. Relay module is used to manage the pumps. Keypad is used as input unit for the system through which different modes are selected and based on these modes relay will be switched ON.

Water level sensor is used to sense level of water in the chamber. 


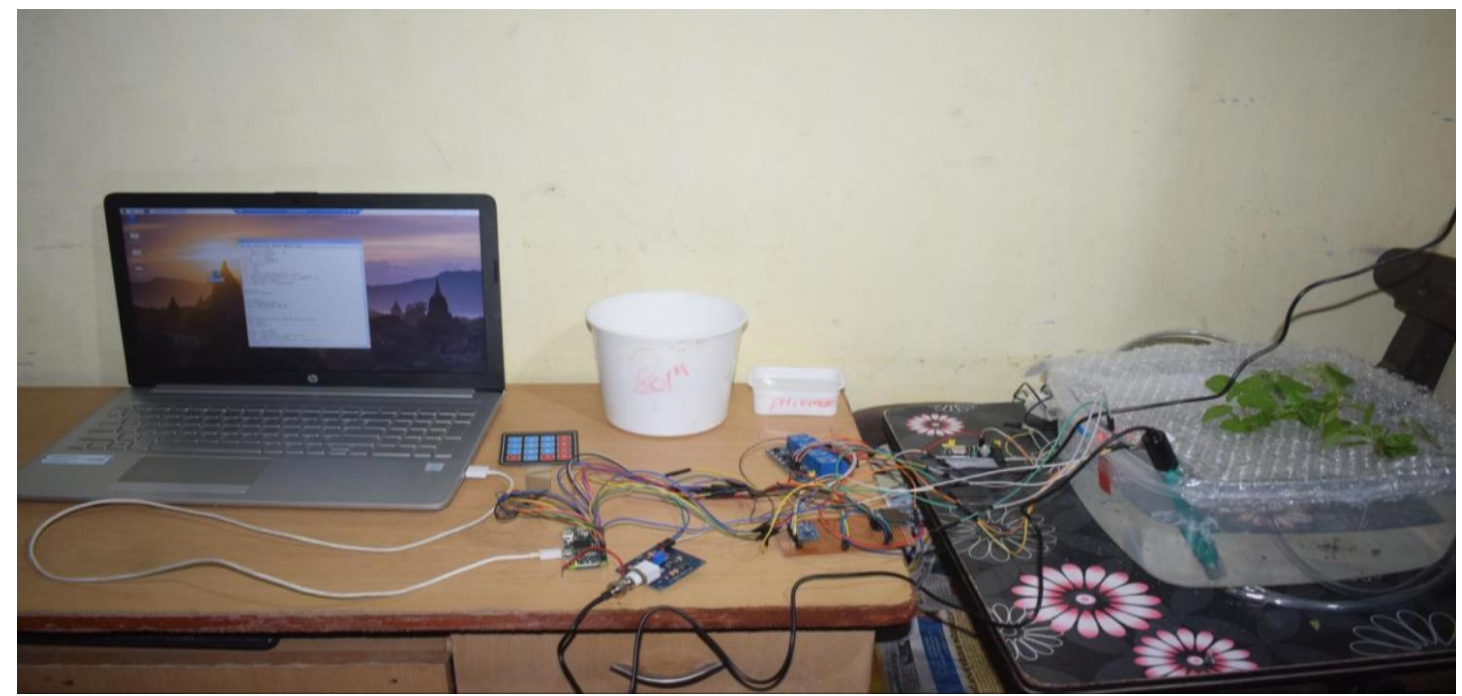

Fig. 6 Complete Hydroponic System

Figure 7 represents the growth of plants after several days.

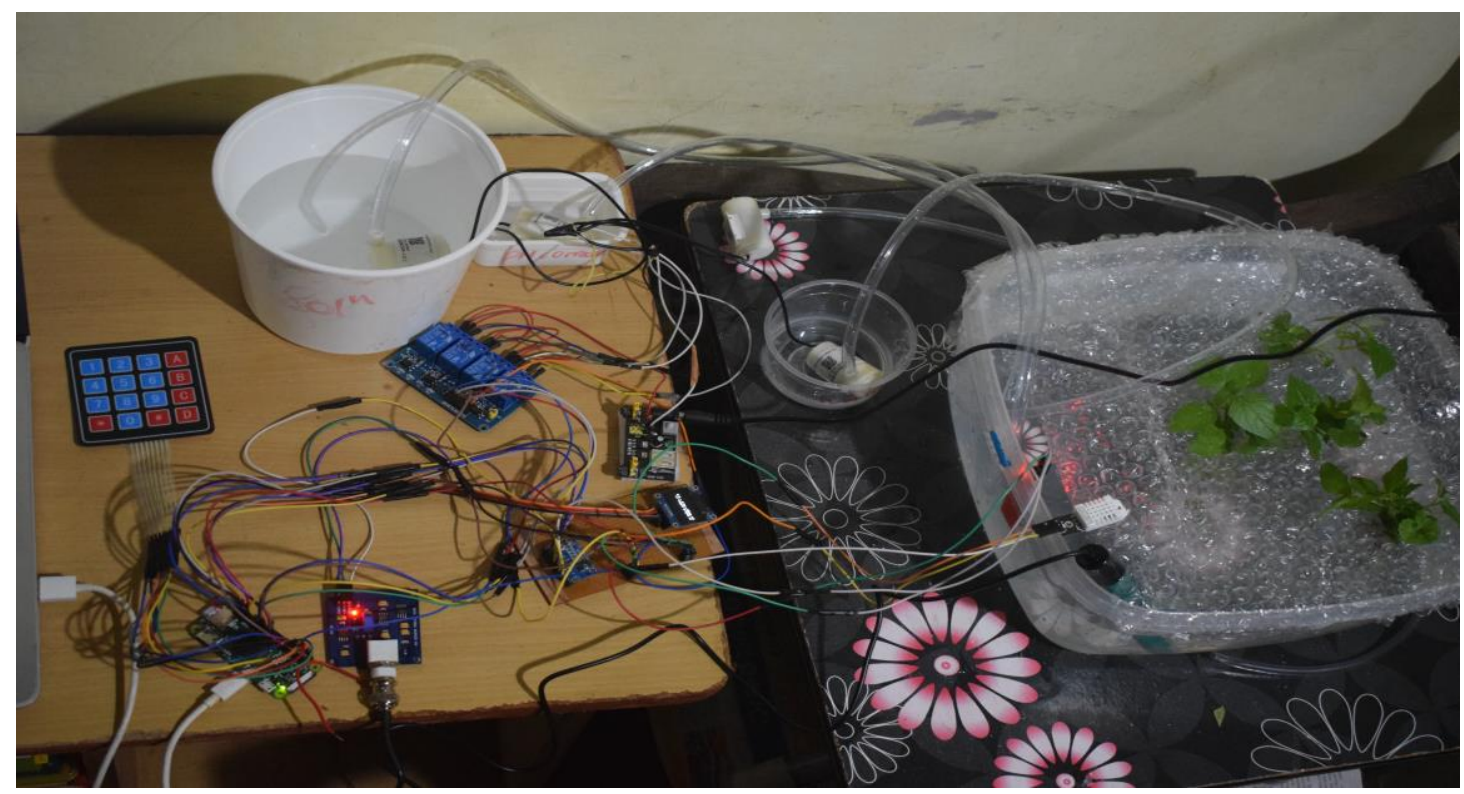

Fig. 7 Growth of plants

\section{Conclusion}

Traditional or old-type farming involved much more manual labor and this method reduce the labor work and same time provide more production using less water than regular agriculture methods used till now. But main issue with Hydroponics is its continuous monitoring of $\mathrm{pH}$ and $\mathrm{EC}$ level of Nutrient Solution along with its surrounding temperature and Humidity range. A better way has been proposed in this project. With our proposed project farmers don't have to continuous monitor its $\mathrm{pH}$ and EC level and control them manual, instead it can be left out to its system to control automatically without presence of farmer. These systems are expected to have a huge impact on agricultural field as they reduce the time and work in performing those tests manually every time.

This project is successful in developing a Fully Automated Hydroponics system which helps in monitoring temperature, Humidity, $\mathrm{pH}$ and EC level in Hydroponics system and control them automatically. This helps the farming community to take preventive and proactive measures to obtain good yield as compared to the traditional farming methods. With our proposed project farmers don't have to continuous monitor its $\mathrm{pH}$ and EC level and control them manual, instead it can be left out to its system to control automatically without presence of farmer. Additional features that can be developed includes App/wireless GSM interface to change mode or values of $\mathrm{pH}$ and EC, to get continuous update with emergency alarm system and to monitor real time data. Small camera can also be used to get live image of the plants. 


\section{References}

[1] Saaid M.F, Sanuddin A, Ali M Yassin M.S.A.I.M, “Automated pH controller system for hydroponic cultivation”, Computer Application \& Industrial Electronics (ISCAIE), 2015 IEEE Symposium.

[2] Lenord M.J.S.M, Sridevi C, "Design of efficient hydroponic nutrient solution control system using soft computing based solution grading", Computation of Power, Energy, Information and Communication (ICCPEIC), 2014 International Conference.

[3] S. Adhau, R. Surwase and K. H. Kowdiki, "Design of fully automated low cost hydroponic system using LabVIEW and AVR microcontroller," 2017 IEEE International Conference on Intelligent Techniques in Control, Optimization and Signal Processing (INCOS), 2017, pp. 1-4, doi: 10.1109/ITCOSP.2017.8303091.

[4] Phutthisathian A, Pantasen N, Maneerat N, "Ontology-Based Nutrient Solution Control System for Hydroponics", Instrumentation, Measurement, Computer, Communication and Control, 2011 First International Conference.

[5] Shaopeng $\mathrm{Hu}$, Kaihua Wu, Haibo Wang, Jiang Chen, "Electrical conductivity measurement method in seawater desalination based on variable frequency excitation", Electronic Measurement \& Instruments, 2009. ICEMI '09. 9th International Conference.

[6] Zulkarnay Z, Shazwani S, Ibrahim B, Jurimah A.J, Ruzairi A.R, Zaridah, S, “An overview on pH measurement technique and application in biomedical and industrial process", Biomedical Engineering (ICoBE), 2015 2nd International Conference.

[7] Saaid M.F, Ali M.S.A.M, Noor M.Z.H, Yahya N.A.M, "A development of an automatic microcontroller system for Deep Water Culture (DWC)", Signal Processing and its Applications (CSPA), 2013 IEEE 9th International Colloquium.

[8] Sheethal, Shradha Shanbhag,Et.Al, Information Science \& Engineering, Canara Engineering College, Survey On Smart Poultry Farm Monitoring System Using Iot, International Journal Of Advance Reasearch In Scienec And Engineering 8(11),2019.

[9] Mohith Raj B J, Mohini Et.Al, Information Science \& Engineering, Canara Engineering College, Survey On Unmanned Aerial Vechicle Based Weeds Detection Using Deep Neural Network, International Journal Of Advance Reaserach In Science And Engineering, 8(9),Sept 2019.

[10] Chethan G Naik, Samyuktha, Information Science \& Engineering, Canara Engineering College, Intergrated Farming System Using IOT and Bluetooth, International Journal Of Advanced Technology In Engineering And Scienece, 7(10), October 2019.

[11] Howard M. Resh, "Hydroponic Food Production: A Definitive Guidebook for the Advanced Home Gardener and the Commercial Hydroponic Grower", Nutrient Solution, CRC Press, Seventh Edition, 2012.

[12] Liu Xuanchao, "The Research on Intelligent Humidity Measurement System", 2010 Second International Conference on Information Technology and Computer Science, 07/2010.

[13] J.Benton Jones Jr, "Tomato Plant Culture in the Field Greenhouse and Home Garden", Greenhouse Tomato Production, CRC Press, Second Edition, 2007.

[14] Feng Chen, Haidong He, and Yongning Tang, "In-situ optimal control of nutrient solution forsoilless cultivation", 2011 3rd International Conference on Advanced Computer Control, 2011.

[15] Brian Gleeson, "High-Temperature Corrosion of Metallic Alloys and Coatings", Materials Science and Technology A Comprehensive Treatment, 03/03/2000.

[16] Mathurkar, Swarup S., Nilesh R Patel, Rahul B. Lanjewar, and Rohit S. Somkuwar. "Smartsensors based monitoring system foragriculture using field programmable gatearray", 2014 International Conference on Circuits Power and Computing Technologies [ICCPCT-2014], 2014.

\section{Authors' Profiles}

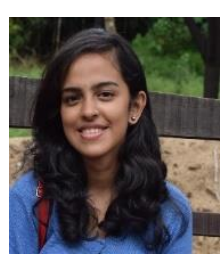

Kshama Pai $\mathbf{K}$ is currently pursuing her B.E. degree in Department of Information and Science, Canara Engineering College, Karnataka, India. Her area of interest is web app developement and Internet of Things.

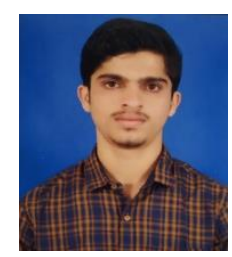

Navaneeth Mallya is currently pursuing his B.E. degree in Department of Information and Science, Canara Engineering College, Karnataka, India. His area of interest is Internet of Things. 
Pratheeksha is currently pursuing her B.E. degree in Department of Information and Science, Canara Engineering College, Karnataka, India. Her area of interest is Internet of Things.

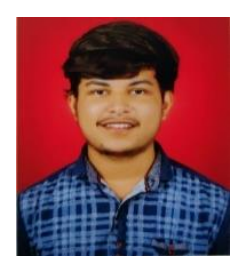

Hariram M Shetty is currently pursuing his B.E. degree in Department of Information and Science, Canara Engineering College, Karnataka, India. His area of interest is Machine Learning and Internet of Things.

How to cite this paper: Hariram M Shetty, Kshama Pai K, Navaneeth Mallya, Pratheeksha, " Fully Automated Hydroponics System for Smart Farming", International Journal of Engineering and Manufacturing (IJEM), Vol.11, No.4, pp. 33-41, 2021. DOI: 10.5815/ijem.2021.04.04 